\title{
Cardiac Stem Cell Therapy, Resident Progenitor Cells and The Role of Cellular Signalling; A Review
}

\author{
Greg Hutchings ${ }^{1}$, Mariusz J. Nawrocki², Paul Mozdziak³, Bartosz Kempisty ${ }^{2,4,5}$
}

\begin{abstract}
Cardiovascular disease (CVD) remains the most common cause of death worldwide. Unhealthy lifestyle choices promote an upward trend of primary risk factors for CVD. As a result, novel methods of treatment are required. The myocardium itself could serve as a source of treatment, via resident cardiac progenitor cells (CPC). A brief overview of current studies and findings related to the potential of differentiation of CPCs to form mature cardiomyocytes (CM) and thereby heal damaged myocardial tissue, as well as implications of these findings for further research areas and possible treatments, is offered. Also investigated is the possible role of CM cell reprogramming, cardiac fibroblasts and signalling molecules in treatment of CVD.
\end{abstract}

Running title: Cardiac stem cells - review

Keywords: cardiac progenitor, cardiomyocyte, stem cell

* Correspondence: bkempisty@ump.edu.pl

Full list of author information is available at the end of article 


\section{Introduction}

CVD is the most prevalent mortality type worldwide, with an approximate $31 \%$ of deaths related to some form of CVD in 2016 [1]. In addition, it is estimated in Europe that CVD is the cause of $45 \%$ of deaths per year [2]. Two of the main risk factors in development of cardiovascular disease are obesity, stemming from poor diet, lack of physical activity, and smoking. These lifestyle choices can lead to hypertension, high blood cholesterol, atherosclerosis, all increasing likelihood of CVD.

The World Health Organisation (WHO) reports that over $10 \%$ of the population are now characterised as obese, including 124 million children, with trends showing a total increase of $2 / 3$-fold since the 1970s [3]. Tobacco use, conversely, has been decreasing steadily since the beginning of the $21^{\text {st }}$ century, with an estimated $0.38 \%$ lower global use between 2010 and 2015, in line with a treaty (WHO Framework Convention Tobacco Control) adopted in 2005 by 168 countries to tackle the issue. However, in $201520.2 \%$ of the population still smoked tobacco, including 29.9\% of Europeans [4]. These surveys show that CVD, developing from poor health due to lifestyle, will continue to be a key health issue globally for decades to come. As a result, new methods and treatments for dealing with CVD are paramount to decreasing global deaths due to the condition.

The most common type of death related to CVD is that of ischaemic (or coronary) heart disease (CHD), which can lead to myocardial infarction and subsequent damage of cardiomyocytes . Cardiac stem cell therapy offers novel treatment methods where resident cardiac progenitor cells may allow regeneration of damaged cardiac tissue. Upon implantation, stem cells may trigger resident progenitor cells. These CPCs, upon activation, can differentiate into new cardiomyocytes or endothelial cells [5]. Notably, most of the benefits from these treatment methods are indirect, in that the implanted cells only make up a small percentage of new cardiomyocytes and blood vessels formed [6]. Thus, intercellular signalling may play a vital role in stem cell implantation. Exosomes are extracellular vesicles which constitute a key component of stem cell therapy, which is a form of paracrine signalling, where the exosomes transport key molecules from donor to recipient cells [7].

Although there is great potential for these treatment methods, there are many obstacles still to be overcome. For example, there remains a debate in the field regarding the potential of resident CPC's to differentiate into cardiomyocytes in the adult mammalian heart. A recent study demonstrated the conversion of non-myocyte to myocyte in the embryo, but not in adult myocardium [8]. As the adult heart is resistant to endogenous repair and shows limited potential for self-renewal and regeneration, a better understanding of the mechanisms, signalling pathways and different cell types involved is necessary to develop effective treatments [5].

\section{Recent studies on the potential of cardiac progenitor cells and cardiac stem cell therapy: A highlight of different approaches to the problem \\ Cardiac Progenitor Cells}

Several distinct types of CPCs have been identified by their unique cellular markers, such as c-Kit+, Sca-1+, Islet-1+, cardiosphere-derived cells, the side population, epicardium derived cells and c-CFU-Fs [9]. A small number of key studies and clinical trials have set the groundwork for modern research areas in CPC treatments.

The SCIPIO (Stem Cell Infusion in Patients with Ischemic CardiOmyopathy) trial published in 2011 demonstrated that c-kit+ cells, when infused in patients with post infarction left-ventricular dysfunction, could significantly improve heart health, even a year after treatment. As well as reporting no adverse effects in patients following treatment, SCIPIO highlighted that endogenous stem cells of the heart could be isolated and expanded from a small amount of myocardium harvested during heart surgery [10].

The CADUCEUS (CArdiosphere-Derived aUtologous stem CElls to reverse ventricUlar dysfunction) trial in 2012 was an investigation to determine efficacy of treating myocardial infarction with cardiosphere-derived stem cells (CDCs) in patients vs. standard care. The results suggested that CDCs were a safe and effective treatment option, and played a role in increasing viable myocardial tissue, possibly through paracrine signalling. Although improvement of heart health via significant loss of scarred tissue was reported, there was no notable increase in left ventricular ejection fraction. Regardless, this form of treatment was shown to increase heart health significantly better than c-Kit+ and bone marrow-derived stem cells [11].

A 2013 study claimed that c-Kit+ cells held the potential for differentiation into CMs and subsequent proliferation and healing of the myocardium [12]. In contrast, a 2015 study demonstrated that C-kit+ cells were endothelial progenitor cells and not CPCs [13]. In 2018, it was also concluded that Sca-1+ cells were not CPCs [14]. Cardiosphere-derived cells have shown some promise to improve cardiac health following injury, however, no studies have demonstrated convincing differentiation of these progenitor populations into mature cardiomyocytes $[8,15]$.

\section{Paracrine factors; small signalling molecules and growth factors \\ Exosomes}

Paracrine cell signalling involving exosomes plays a key role in the interaction between donor and recipient cells upon implantation [16]. This form of intercellular communication allows horizontal transfer of genetic information between stem and resident adult cells via extracellular vesicles. Several studies have demonstrated that the exosomes of cardiac cells may be vital to their capacity for renewal $[6,17]$. 
Recent studies have shown that CPC exosomes (CPCe) and bone marrow derived mesenchymal stem cell exosomes (BMCe) can both promote angiogenesis $[6,18]$. Injection of CPCe into the heart following induction of myocardial infarction in rats resulted in a larger capacity for healing and improved function when compared with BMCe or control. It is hypothesised that $\mathrm{BMCe}$ offer less protection against oxidative stress than CPCe, which are also associated with higher levels of proteins such as PAPP-A, a protease which releases IGF-1 (known to have a cardioprotective role) [6]. Important to note is the finding that exosomal cargo can be manipulated by changing parental cellular conditions, for example, inducing hypoxia.

\section{Retinoic acid}

A recent study suggests that retinoic acid (RA), as well as being crucial for guiding correct development of the embryo via intercellular signalling, may also play a role in cardiac repair. Retinoic acid receptor (RAR) agonists were shown to be potent proliferators of CPCs [19]. Importantly, new CPCs formed maintained their progenitor phenotype. All-Trans Retinoic Acid (ATRA) and AM580 were 2 RAR agonists identified and shown to increase proliferation of induced pluripotent stem cell derived - CPCs. Additionally, the ATRA compounds did not increase proliferation of terminal cardiac cell types [19]. Whether ATRA and AM580 hold therapeutic value in future treatments remains to be investigated. A previous study demonstrated the importance of RA in heart health by noting that blocking signalling of this molecule in chick embryo myocardium inhibited cardiomyocyte proliferation. It was suggested that erythropoietin and retinoic acid work in tandem to regulate signalling in the developing heart [20].

\section{Insulin Growth Factor-1}

Low blood levels of IGF-1 have been shown to correlate with poor heart health and death of CPCs. IGF1 treatment was shown to improve cardiomyopathy, decreasing apoptosis, restoring heart metabolism and cardiac gap junctions [21]. It is believed that by upregulation of the Akt pathway (shown experimentally by the pAkt/Akt ratio), IGF-1 is cardioprotective and promotes survival and differentiation of CPCs. In vitro, treatment of pig CPCs with IGF-1 had potential to reduce adverse cardiac remodelling and promote regeneration of the myocardium [22].

\section{Cardiomyocyte renewal and the cell cycle Control of the cell cycle and RNA interference}

Suppressing cell cycle inhibitors may promote cardiomyocyte proliferation potential. Specifically, downregulating Retinoblastoma1 (Rb1) and Meis Homeobox 2 (Meis2), via small interfering (si)RNA's, induced proliferation of CMs in rats and human cell models and had a positive effect on heart health and improved wound healing [23].
The in vivo experimental methods involved siRNA-infused hydrogel injection to the myocardium following ischaemic heart injury in rats. Interestingly, separate inhibition of either of these genes did not result in significant proliferation. Additionally, control injections of hydrogel alone without siRNAs still offered a small degree of cardio-protection, suggesting that intracardiac injection of biological materials following acute myocardial injury may have some small therapeutic benefits. The results of RT-PCR, Western Blot and immunohistochemical analysis together suggested a site-specific induction of CM cell cycle re-entry, keeping the potential low for off-site pathogenic effects such as unintended hyperplasia [23]. Previous attempts to induce re-entry of CMs into the cell cycle have resulted in heart dysfunction. Notably, the hydrogel technology holds promise as a new delivery method for donor stem cells [24].

Although the results of this experiment highlight a potential treatment for ischaemia, it is important to note that the number of new cardiomyocytes formed is still too low to effectively replace damaged myocardium.

Four cell cycle regulators (CDK1:CCNB and CDK4:CCND complexes) and subsequent intramyocardial delivery induced cardiomyocyte proliferation in vivo with an efficiency of over $15 \%$. Similarly, cardiomyocytes' stimulated re-entry into the cell cycle promoted mitosis and increased cardiac health significantly. The same study suggests that use of Wee1 and TGF $\beta$ inhibitors may prevent inactivation of endogenous CDK1:CCNB complexes and thus remove the need of delivery of these compounds [25].

MicroRNAs are a class of non-coding RNA found to regulate gene expression post-transcriptionally. The cluster miR 302-367, previously shown to be connected to regulation of CM proliferation in the adult heart, was demonstrated to significantly increase CM proliferation after delivery via hydrogel injection. Overall heart health increased when compared with controls demonstrating that delivery of relevant biomaterials, without implantation of stem cells, could play a key role in future therapeutic options $[26,27]$.

\section{Hypoxia}

Hypoxia was shown in 2012 to upregulate Pax7 and downregulate MyoD, encouraging self-renewal and reducing differentiation of muscle progenitor cells. As a result, these satellite cells are maintained in an undifferentiated state [28]. As previously mentioned, hypoxic injury to cardiomyocyte cells may trigger paracrine factors to induce proliferation of CMs.

Hypoxia is known to reduce $\mathrm{CM}$ proliferation in the hearts of developing rats $[29,30]$. A population of hypoxic cardiomyocytes in transgenic mice improved CM proliferation in the adult heart, suggesting that hypoxic cell signalling plays an impor- 
tant role in CM cell cycling [31]. It is possible that induction of CM proliferation may be based on developmental stage of cells $[30,32,33]$. The changing effects of hypoxia on CMs across developmental stages may be linked to changes in structure and composition from embryo to adult [33]. By reducing presence of reactive oxygen species, hypoxia may benefit CM proliferation [32].

Hypoxic mesenchymal stem cells, upon implantation, had a reversal on cardiac fibrosis via prevention of fibroblast to myofibroblast transition [34].

\section{Cardiac Fibroblasts and Resident Immune Cells}

Cardiac fibroblasts (CF) constitute a cell population known to play a role in repair and regeneration of cardiomyocytes, for example, in myocardial remodelling following injury. CF are the most populous cell type in the heart, surrounding myocardial layers and providing support to cardiac development, function, and structure via synthesis of extracellular matrix components.

Contrary to CMs, CFs have large capacity for proliferation and thus play a key role in the repair process of the heart, mounting an inflammatory response along with immune cells and subsequent repair via fibrosis. Because CMs hold such low potential for self-renewal, the remodelling of myocardial tissue by fibrosis following injury is inadequate to maintain heart health.

Although resident cardiac immune cells have been shown to contribute to inflammation and fibrosis, in general they are believed to have a minimally inflammatory role and promote angiogenesis [35]. Better understanding of the interactions between CMs, CFs and immune cells following acute injury is important to guide future research [36].

Because cardiac fibroblasts represent a heterogenous population with no specific cell markers, they are among the least characterised cell types relevant to heart health [37]. Although adult CFs promote cardiomyocyte hypertrophy, it has been shown that embryonic CFs contribute to proliferation of CMs through paracrine signalling [38].

Previous experiments demonstrate that overexpression of specific transcription factors, (Gata4, Mef2c and Tbx5) reprogram cardiac fibroblasts into mature cardiomyocytes $[39,40]$. These 3 transcription factors co-operate in activating cardiac gene expression and promoting CM differentiation.

\section{Twist-2 Transcription Factor and Twist2 Expressing Cells (TEC)}

Twist transcription factors act as regulators of cell fate across organisms. In mice, a population of cells expressing Twist2 (TEC) were shown to contribute to the development of new cardiomyocytes, endothelial cells and fibroblasts using lineage tracing techniques. Notably, this cell type may be able to induce proliferation by fusion with existing cardiomyocytes
[41]. It is believed that this TEC cell type may play a pivotal role in maintenance of cardiac function, although more research in the area is necessary.

\section{Possible future areas of study involving cardiomyocytes and resident progenitor cells}

All cell types of the heart appear to play an important role in cardiac repair, such as fibroblasts, cardiomyocytes, resident CPCs and immune cells. Recent discovery of Twist2 expressing cells affecting CM proliferation highlights a lack of understanding and characterisation of all cell types involved. Evidence indicates that small signalling molecules and growth factors may also have an important role in regulation of CPC proliferation.

Whether the most promise for treatment of cardiovascular disease lies in triggering proliferation of CMs, CFs, resident CPCs, a combination of these techniques, or some other avenue remains to be investigated. Cardiomyocytes, by induced re-entry into the cell cycle, may undergo mitosis and contribute to new myocardial tissue. Resident CPCs may be treated with small signalling molecules to induce proliferation. Whether these CPCs differentiate into mature CMs in the adult heart is a topic of current debate.

After implantation, incorporation of the donor cells via sustained engraftment and correct electric coupling is necessary. Studies have shown that less than $10 \%$ of implanted stem cells survive more than 4 weeks [42]. A better understanding of cellular signalling may reveal methods to improve this treatment area. Improved technologies may hold potential for new delivery methods of donor cells e.g. via hydrogel [24].

Other treatment options with potential for effective heart repair include manipulation of exosomal cell signalling by changing cellular conditions (e.g. by inducing hypoxia), manipulation of gene expression through RNA interference, or lineage reprogramming of cardiac fibroblasts to CMs via transcription factors.

A combination of the above-mentioned methods could prove the most effective treatment option for cardiovascular disease within grasp of current technologies. Future studies could highlight novel therapeutic options with improved success rate, lower risk to patients, and reduced costs.

\section{Unanswered Questions - A summary of areas where more study is required, including identified gaps in knowledge in the literature, conflicting studies and ongoing debates}

Annual cardiomyocyte turnover in the adult heart is reported to reduce from $1 \%$ at age 25 to $0.45 \%$ at age 75 [43]. Before treatments involving inducing $\mathrm{CM}$ proliferation can be implemented, a comparative analysis of the potential of siRNAs, miRNAs and transcription factors to induce proliferation must be gathered [44]. Rate of proliferation 
induced must be accurate to avoid possibility of heart dysfunction, taking into account the nature of the particular heart (ie. an adolescent's heart vs. a 75-year old's heart).

An understanding of the effects of inducing hypoxia in the heart to stimulate proliferation is required. The effects of hypoxia on the myocardium are known to be linked to the developmental stages of the organism. Further study is required to uncover potential of a possible therapeutic treatment [30,33].

A standardized/optimal method of isolating and purifying exosomes from cells of interest is yet to be achieved $[7,45]$. It has been suggested that the capacity for CPCs to heal the damaged myocardium may be related to exosomal signalling $[17,46]$. Manipulation of these extracellular vesicles may offer an alternative, or complementary treatment to implantation. Exosomes may also serve an important use as biomarkers of disease [47].

\section{Differentiation of CPCs into CMs}

Identification of intracellular markers of CPCs and $\mathrm{CMs}$ is required to study and determine the nature of cell lineage and proliferation of CMs in the adult heart.A summary of discovered progenitor cell types associated with the heart and their properties is presented in table $\mathbf{1}$.

There are ongoing debates related to definitions of cell lineage in cardiac stem cells. Originally believed to have no capacity for self-renewal due to mature cardiomyocytes' exit from the cell cycle, the heart is now believed to be residence to several different populations of stem or progenitor cells, with the potential for cardiac repair [48]. These cells are speculated to originate from a single cardiac stem cell type, and the different populations to represent different physiological stages of the parent stem cell [49]. However, the exact source of these resident progenitor cells have not been discovered.

Recently, doubt has been cast over the possibility of a single cardiac parent stem cell type [13]. The potential of CPCs to differentiate into new cardiomyocytes is limited to early development of the embryo and is minimal in the adult heart, suggesting that any new cardiomyocytes formed in the adult heart are derived from other cardiomyocytes [8].

To summarise, optimising treatments for CVD to maximise angiogenesis and cardiomyocyte proliferation, minimise fibrosis and diverse myocardial remodelling, may involve cell types including CPCs, CMs, CFs

TABLE 1 Summary of Distinct CPC populations. List of CPCs discovered, species cell type identified in, cell lineages associated with cell type, cellular markers defining unique cell type, literature used to gather information

\begin{tabular}{|c|c|c|c|c|}
\hline $\begin{array}{c}\text { CPC } \\
\text { POPULATION } \\
\end{array}$ & SPECIES & $\begin{array}{c}\text { ASSOCIATED CELL } \\
\text { LINEAGES } \\
\end{array}$ & CELLULAR MARKERS & REFERENCES \\
\hline c-Kit+ & $\begin{array}{l}\text { Human, mouse, } \\
\text { rat, dog, pig }\end{array}$ & Endothelial & $\begin{array}{l}\text { c-Kit+, CD34-, CD45-, Sca-1+, } \\
\text { Abcg2+, CD105+, CD166+, } \\
\text { GATA4+, NKX2-5+/-, MEF2c+ }\end{array}$ & [9] [47] \\
\hline Sca-1+ & Mouse & $\begin{array}{l}\text { Endothelial, Smooth } \\
\text { muscle }\end{array}$ & $\begin{array}{l}\text { Sca-1+, CD105+, CD34-, CD45- } \\
\text {, FLK1-, c-Kit+/-, GATA4+, } \\
\text { NKX2-5+/-, MEF2C+ }\end{array}$ & {$[9][47]$} \\
\hline $\begin{array}{l}\text { Epicardium-deri- } \\
\text { ved cells }\end{array}$ & Human, mouse & $\begin{array}{l}\text { Mesenchymal, fibroblast, } \\
\text { smooth muscle }\end{array}$ & $\begin{array}{l}\text { CD34+, c-Kit+/-, CD44+, } \\
\text { CD90+, CD105+, CD46+ }\end{array}$ & [9] [47] \\
\hline $\begin{array}{l}\text { Cardiosphere-de- } \\
\text { rived cells }\end{array}$ & $\begin{array}{l}\text { Human, mouse, } \\
\text { rat, dog, pig }\end{array}$ & $\begin{array}{l}\text { Cardiomyocytes, endothe- } \\
\text { lial, smooth muscle }\end{array}$ & $\begin{array}{l}\text { CD31+, CD34+, c-Kit(low), } \\
\text { Sca1+, CD45+, CD105+, } \\
\text { Abcg2+ }\end{array}$ & [9] [47] \\
\hline Islet-1+ & $\begin{array}{l}\text { Mouse, rat, } \\
\text { human }\end{array}$ & $\begin{array}{l}\text { Second heart field, Cardiac } \\
\text { neural crest }\end{array}$ & $\begin{array}{l}\text { Isl-1+, CD31-, Sca-1-, c-Kit+/-, } \\
\text { GATA4+, NKX2-5+ }\end{array}$ & [9] [47] \\
\hline $\begin{array}{l}\text { Side Population } \\
\text { Cells }\end{array}$ & Mouse, rat & $\begin{array}{l}\text { Cardiomyocyte, fibroblast, } \\
\text { endothelial, smooth muscle }\end{array}$ & $\begin{array}{l}\text { CD34+, CD45+, Abcg2+, Sca- } \\
\text { 1+, c-Kit+, NKX2-5-, GATA4- }\end{array}$ & [9] [47] \\
\hline $\begin{array}{l}\text { Cardiac colony } \\
\text { forming unit } \\
\text { fibroblasts }\end{array}$ & Mouse & Mesenchymal & $\begin{array}{l}\text { PDGFR-a+, Sca-1+, CD31-, } \\
\text { CD90+, c-Kit(low), CD45-, } \\
\text { FLK1-, CD44+, CD29+, CD105+ }\end{array}$ & [9] [47] \\
\hline
\end{tabular}


and resident immune cells, as well as small signalling molecules such as exosomes and growth factors. Further study into the interactions and signalling mechanisms of these cell types and molecules is necessary.

\section{Conclusions}

Cardiac stem cell therapy offers a potentially cheaper, safer and more effective treatment option than current therapies. CVD is still the number one cause of death worldwide, and it will remain an important issue for study to improve world-wide health standards. However, novel treatment methods for cardiac disorders derived from stem cell research are not yet within reach, due to the complicated nature of cell lineages in the heart.

More experiments investigating the nature of cardiac progenitor cells and their role in cardiac repair are vital to improving human health. Whether non-myocyte differentiation into myocyte cells in the adult human heart is possible remains controversial, providing obstacles for future research. Additionally, recent studies have highlighted the important roles of small signalling molecules and growth factors in repair of damaged myocardium. Further studies in this area may highlight viable alternatives to stem cell implantation, such as delivery of biomaterials via hydrogel injection. The role of hypoxia in proliferation of CMs and paracrine signalling is not fully understood and should be explored to possibly expand treatment options.

It is possible that a combination of different treatment methods from those noted above, may lead to vast improvements in cardiac therapy, through development of the ability to manipulate and increase the capacity of the human heart for self-renewal.

\section{Ethical approval}

The conducted research is not related to either human or animal use.

\section{Corresponding author}

Bartosz Kempisty, Department of Anatomy, Poznan University of Medical Sciences, 6 Święcickiego St., 60-781 Poznań, Poland, Tel./ Fax: +48618546565, e-mail: bkempisty@ump.edu.pl.

\section{Conflict of interest statement}

The authors declare they have no conflict of interest.

\section{References}

1. World Health Organisation. Cardiovascular diseases (CVDs) 2017https://www.who.int/news-room/fact-sheets/detail/cardiovascular-diseases-(cvds) (accessed September 15, 2019).

2. Wilkins E, L. W, Wickramasinghe K, P B. European Cardiovascular Disease Statistics 2017 edition. Eur Hear Netw. 2017:8-15; 94, 118, 127, $149,162,174$.

3. World Health Organisation. Obesity and overweight 2018https://www. who.int/news-room/fact-sheets/detail/obesity-and-overweight (accessed September 15, 2019).

4. WHO global report on trends in prevalence of tobacco smoking 20002025 , second edition ISBN 978-92-4-151417-0.

5. Amini H, Rezaie J, Vosoughi A, Rahbarghazi R, Nouri M. Cardiac progenitor cells application in cardiovascular disease. J Cardiovasc Thorac Res. 2017;9:127-32; DOI:10.15171/jcvtr.2017.22.

6. Barile L, Cervio E, Lionetti V, Milano G, Ciullo A, Biemmi V, Bolis S, Altomare C, Matteucci M, Di Silvestre D, Brambilla F, Fertig TE, Torre T,
Demertzis S, Mauri P, Moccetti T, Vassalli G. Cardioprotection by cardiac progenitor cell-secreted exosomes: Role of pregnancy-associated plasma protein-A. Cardiovasc Res. 2018;114:992-1005; DOI:10.1093/cvr/ cvy055.

7. Gartz M, Strande JL. Examining the paracrine effects of exosomes in cardiovascular disease and repair. J Am Heart Assoc. 2018;7:1-13; DOI:10.1161/JAHA.117.007954.

8. Li Y, He L, Huang X, Bhaloo SI, Zhao H, Zhang S, Pu W, Tian X, Li Y, Liu Q Yu W, Zhang L, Liu X, Liu K, Tang J, Zhang H, Cai D, Ralf AH, Xu Q Lui KO, Zhou B. Genetic lineage tracing of nonmyocyte population by dual recombinases. Circulation. 2018;138:793-805; DOI:10.1161/ CIRCULATIONAHA.118.034250.

9. Le T, Chong J. Cardiac progenitor cells for heart repair. Cell Death Discov. 2016;2:1-4; DOI:10.1038/cddiscovery.2016.52.

10. Bolli R, Chugh AR, D'Amario D, Loughran JH, Stoddard MF, Ikram S, Beache GM, Wagner SG, Leri A, Hosoda T, Sanada F, Elmore JB, Goichberg P, Cappetta D, Solankhi NK, Fahsah I, Rokosh DG, Slaughter MS, Kajstura J, Anversa P. Cardiac stem cells in patients with ischaemic cardiomyopathy (SCIPIO): Initial results of a randomised phase 1 trial. Lancet. 2011;378:1847-57; DOI:10.1016/S0140-6736(11)61590-0.

11. Makkar RR, Smith RR, Cheng K, Malliaras K, Thomson LEJ, Berman D, Czer LSC, Marbán L, Mendizabal A, Johnston P V, Russell SD, Schuleri KH, Lardo AC, Gerstenblith G, Marbán E. NIH Public Access 2015;379:895904; DOI:10.1016/S0140-6736(12)60195-0.Intracoronary.

12. Ellison GM, Vicinanza C, Smith AJ, Aquila I, Leone A, Waring CD, Henning BJ, Stirparo GG, Papait R, Scarfò M, Agosti V, Viglietto G, Condorelli G, Indolfi C, Ottolenghi S, Torella D, Nadal-Ginard B. Adult c-kitpos cardiac stem cells are necessary and sufficient for functional cardiac regeneration and repair. Cell. 2013;154:827-42; DOI:10.1016/j.cell.2013.07.039.

13. Sultana N, Zhang L, Yan J, Chen J, Cai W, Razzaque S, Jeong D, Sheng W, Bu L, Xu M, Huang GY, Hajjar RJ, Zhou B, Moon A, Cai CL. Resident c-kit + cells in the heart are not cardiac stem cells. Nat Commun. 2015;6:1-10; DOI:10.1038/ncomms9701.

14. Vagnozzi RJ, Sargent MA, Lin SCJ, Palpant NJ, Murry CE, Molkentin JD. Genetic lineage tracing of Sca-1+ cells reveals endothelial but not myogenic contribution to the murine heart. Circulation. 2018;138:2931-9; DOI:10.1161/CIRCULATIONAHA.118.035210.

15. Gallet R, Marban E. Cardiosphere - derived cells and exosomes secreted by such cells in the treatment of heart failure with preserved ejection fraction. Vol. 1. 2019.

16. Han C, Sun X, Liu L, Jiang H, Shen Y, Xu X, Li J, Zhang G, Huang J, Lin Z, Xiong N, Wang T. Exosomes and their therapeutic potentials of stem cells. Stem Cells Int. 2016;2016; DOI:10.1155/2016/7653489.

17. Xu MY, Ye ZS, Song XT, Huang RC. Differences in the cargos and functions of exosomes derived from six cardiac cell types: A systematic review. Stem Cell Res Ther. 2019;10:1-11; DOI:10.1186/s13287-019-1297-7.

18. Page C. Cellular Communication in Cardiac Regeneration Janita A . Maring. 2019.

19. Drowley L, McPheat J, Nordqvist A, Peel S, Karlsson U, Martinsson S, Müllers E, Dellsén A, Knight S, Barrett I, Sánchez J, Magnusson B, Greber B, Wang QD, Plowright AT. Discovery of Retinoic Acid Receptor Agonists as Proliferators of Cardiac Progenitor Cells Through a Phenotypic Screening Approach n.d. Stem Cells Translational Medicine. 2019. DOI:10.1002/sctm.19-0069.

20. Stuckmann I, Evans S, Lassar AB. Erythropoietin and retinoic acid, secreted from the epicardium, are required for cardiac myocyte proliferation 2003;255:334-49; DOI:10.1016/S0012-1606(02)00078-7.

21. Andrade D, Oliveira G, Menezes L, Nascimento AL, Stumbo AC, Thole A, Garcia-souza É, Carvalho L, Cortez E. Insulin-like growth factor-1 short-period therapy improves cardiomyopathy stimulating cardiac progenitor cells survival in obese mice. Nutr Metab Cardiovasc Dis. 2019; DOI:10.1016/j.numecd.2019.09.001.

22. Perez-martinez C, Prado P De, Vicinanza C, Purushothaman S, Bs C Galuppo V, Iaconetti C, Waring CD, Smith A, Torella M, Ramon CC, Gonzalo-orden JM, Agosti V, Indolfi C, Galiñanes M, Fernandez-vazquez F Nadal-ginard B. Endogenous Cardiac Stem Cell Activation by Insulin-Like Growth Factor-1 / Hepatocyte Growth Factor Intracoronary Injection Fosters Survival and Regeneration of the Infarcted Pig Heart. JAC. 2011;58:977-86; DOI:10.1016/j.jacc.2011.05.013.

23. Alam P, Haile B, Arif M, Pandey R, Rokvic M, Nieman M, Maliken BD, Paul A, Wang Y, Sadayappan S, Ahmed RPH, Kanisicak O. Inhibition of Senescence-Associated Genes Rb1 and Meis2 in Adult Cardiomyocytes Results in Cell Cycle Reentry and Cardiac Repair Post-Myocardial Infarction . J Am Heart Assoc. 2019;8; DOI:10.1161/jaha.119.012089.

24. Shin J, Choi S, Kim JH, Cho JH, Jin Y, Kim S, Min S, Kim SK, Choi D, Cho S. Tissue Tapes - Phenolic Hyaluronic Acid Hydrogel Patches for Off-the-Shelf Therapy 2019;1903863:1-15; DOI:10.1002/adfm.201903863.

25. Mohamed TMA, Ang YS, Radzinsky E, Zhou P, Huang Y, Elfenbein A Foley A, Magnitsky S, Srivastava D. Regulation of Cell Cycle to Stimu- 
late Adult Cardiomyocyte Proliferation and Cardiac Regeneration. Cell. 2018;173:104-116.e12; DOI:10.1016/j.cell.2018.02.014.

26. Jha S, Rollins MG, Fuchs G, Procter DJ, Hall EA, Cozzolino K, Sarnow P, Savas JN, Walsh D. HHS Public Access 2017;546:651-5; D0I:10.1038/ nature22814.Trans-kingdom.

27. Gao Z, Zhu X, Dou Y. The MIR-302/367 cluster: A comprehensive update on its evolution and functions. Open Biol. 2015;5; DOI:10.1098/ rsob.150138.

28. Liu W, Wen Y, Bi P, Lai X, Liu XS, Liu X, Kuang S. Hypoxia promotes satellite cell self-renewal and enhances the efficiency of myoblast transplantation. Dev. 2012;139:2857-65; DOI:10.1242/dev.079665.

29. Tong W, Xiong F, Li Y, Zhang L. Hypoxia inhibits cardiomyocyte proliferation in fetal rat hearts via upregulating TIMP-4. Am J Physiol - Regul Integr Comp Physiol. 2013;304:613-20; DOI:10.1152/ajpregu.00515.2012.

30. Paradis AN, Gay MS, Wilson CG, Zhang L. Newborn hypoxia/anoxia inhibits cardiomyocyte proliferation and decreases cardiomyocyte endowment in the developing heart: Role of endothelin-1. PLoS One. 2015;10:1-21; DOI:10.1371/journal.pone.0116600.

31. Kimura W, Xiao F, Canseco DC, Muralidhar S, Thet S, Zhang HM, Abderrahman Y, Chen R, Garcia JA, Shelton JM, Richardson JA, Ashour AM, Asaithamby A, Liang H, Xing C, Lu Z, Zhang CC, Sadek HA. Hypoxia fate mapping identifies cycling cardiomyocytes in the adult heart. Nature. 2015;523:226-30; DOI:10.1038/nature14582.

32. Nakada Y, Canseco DC, Thet S, Abdisalaam S, Asaithamby A, Santos CX, Shah AM, Zhang H, Faber JE, Kinter MT, Szweda LI, Xing C, Hu Z, Deberardinis RJ, Schiattarella G, Hill JA, Oz O, Lu Z, Zhang CC, Kimura W, Sadek HA. Hypoxia induces heart regeneration in adult mice. Nature. 2017;541:222-7; DOI:10.1038/nature20173.

33. Sun Y, Jiang C, Hong H, Liu J, Qiu L, Huang Y, Ye L. Effects of hypoxia on cardiomyocyte proliferation and association with stage of development. Biomed Pharmacother. 2019;118:109391; DOI:10.1016/j. biopha.2019.109391.

34. Zhuang LEI, Xia W, Hou M. Co - culturing with hypoxia pre-conditioned mesenchymal stem cells as a new strategy for the prevention of irradiation-induced fibroblast - to - myofibroblast transition 2019:1-12 DOI:10.3892/or.2019.7293.

35. Patel B, Bansal SS, Ismahil MA, Hamid T, Rokosh G, Mack M, Prabhu SD. CCR2+ Monocyte-Derived Infiltrating Macrophages Are Required for Adverse Cardiac Remodeling During Pressure Overload. JACC Basic to Transl Sci. 2018;3:230-44; DOI:10.1016/j.jacbts.2017.12.006.

36. Psarras S, Beis D, Nikouli S, Tsikitis M, Capetanaki Y. Three in a Box: Understanding Cardiomyocyte, Fibroblast, and Innate Immune Cell Interactions to Orchestrate Cardiac Repair Processes. Front Cardiovasc Med. 2019;6:1-23; DOI:10.3389/fcvm.2019.00032.

37. Doppler SA, Carvalho C, Lahm H, Deutsch MA, Dreßen M, Puluca N Lange R, Krane M. Cardiac fibroblasts: More than mechanical support. J Thorac Dis. 2017;9:S36-51; DOI:10.21037/jtd.2017.03.122.

38. Ieda M, Tsuchihashi T, Ivey KN, Ross RS, Hong TT, Shaw RM, Srivastava D. Cardiac Fibroblasts Regulate Myocardial Proliferation through $\beta 1$ Integrin Signaling. Dev Cell. 2009;16:233-44; DOI:10.1016/j. devcel.2008.12.007.

39. Ieda M, Fu JD, Delgado-Olguin P, Vedantham V, Hayashi Y, Bruneau BG, Srivastava D. Direct reprogramming of fibroblasts into functional cardiomyocytes by defined factors. Cell. 2010;142:375-86; DOI:10.1016/j. cell.2010.07.002.

40. Inagawa K, Ieda M. Direct reprogramming of mouse fibroblasts into cardiac myocytes. J Cardiovasc Transl Res. 2013;6:37-45; DOI:10.1007/ s12265-012-9412-5.

41. Min YL, Jaichander P, Sanchez-Ortiz E, Bezprozvannaya S, Malladi VS, Cui M, Wang Z, Bassel-Duby R, Olson EN, Liu N. Identification of a multipotent Twist2-expressing cell population in the adult heart. Proc Natl Acad Sci U S A. 2018;115:E8430-9; DOI:10.1073/pnas.1800526115.

42. Xu J, Xiong YY, Li Q Hu MJ, Huang PS, Xu JY, Tian XQ Jin C, Liu JD, Qian L, Yang YJ. Optimization of Timing and Times for Administration of Atorvastatin-Pretreated Mesenchymal Stem Cells in a Preclinical Model of Acute Myocardial Infarction. Stem Cells Transl Med. 2019;8:1068-1083: DOI: $10.1002 /$ sctm.19-0013

43. Bergmann O, Bhardwaj RD, Bernard S, Zdunek S, Barnabé-Heide $\mathrm{F}$ Walsh S, Zupicich J, Alkass K, Buchholz BA, Druid H, Jovinge S, Frisén J. Evidence for cardiomyocyte renewal in humans. Science. 2009;324:98102; DOI:10.1126/science.1164680.

44. Zebrowski DC, Becker R, Engel FB. Towards regenerating the mammalian heart: Challenges in evaluating experimentally induced adult mammalian cardiomyocyte proliferation. Am J Physiol - Hear Circ Physiol. 2016;310:H1045-54; DOI:10.1152/ajpheart.00697.2015

45. Ayala-Mar S, Donoso-Quezada J, Gallo-Villanueva RC, Pérez-González VH, González-Valdez J. Recent advances and challenges in the recov- ery and purification of cellular exosomes. Electrophoresis. 2019:1-14; DOI:10.1002/elps.201800526.

46. Trac D, Hoffman JR, Bheri S, Maxwell JT, Platt MO, Davis ME. Predicting Functional Responses of Progenitor Cell Exosome Potential with Computational Modeling. Stem Cells Transl Med. 2019; DOI:10.1002/ sctm.19-0059.

47. Li P, Kaslan M, Lee SH, Yao J, Gao Z. Progress in exosome isolation techniques. Theranostics. 2017;7:789-804; DOI:10.7150/thno.18133.

48. Park JH, Lee NK, Lim HJ, Mazumder S, Rethineswaran VK, Kim YJ, Jang WB, Ji ST, Kang S, Kim DY, Van LTH, Giang LTT, Kim DH, Ha JS, Yun J, Kim H, Han J, Mishchenko NP, Fedoreyev SA, Vasileva EA, Kwon SM, Baek SH. Therapeutic cell protective role of histochrome under oxidative stress in human cardiac progenitor cells. Mar Drugs. 2019;17; DOI:10.3390/ md17060368.

49. Birbrair A. Stem Cells Heterogeneity in Different Organs. Advances in Experimental Medicine and Biology. Springer. 2019. 